\title{
A prospective multi-site registry study of a specific protocol of autologous bone marrow concentrate for the treatment of shoulder rotator cuff tears and osteoarthritis
}

\author{
This article was published in the following Dove Press journal: \\ Journal of Pain Research \\ 5 June 2015 \\ Number of times this article has been viewed
}

\author{
Christopher J Centeno' \\ Hasan Al-Sayegh' \\ Jamil Bashir ${ }^{\prime}$ \\ Shaun Goodyear² \\ Michael D Freeman ${ }^{3}$ \\ 'Centeno-Schultz Clinic, Broomfield, \\ CO, USA; ${ }^{2}$ Forensic Research \\ and Analysis, Portland, OR, USA; \\ ${ }^{3}$ Department of Public Health and \\ Preventive Medicine and Psychiatry, \\ Oregon Health and Science \\ University, Portland, OR, USA
}

\begin{abstract}
Introduction: Shoulder pain is a common musculoskeletal complaint in the general population. Bone marrow concentrate (BMC) injections offer promising potential as a minimally invasive approach for treatment of shoulder pain in degenerative disease. In this study, we investigated the clinical outcomes of the BMC injections for treatment of shoulder pain and disability due to osteoarthritis $(\mathrm{OA})$ and rotator cuff tears in a treatment registry population.
\end{abstract}

Methods: A total of 115 shoulders in 102 patients were treated with autologous BMC injections for symptomatic OA at the glenohumeral joint and/or rotator cuff tears. Data were collected for factors potentially influencing outcome, including age, sex, body mass index, and the type of condition treated (ie, OA or rotator cuff tear). Clinical outcomes were assessed serially over time using the disabilities of the arm, shoulder and hand score (DASH), the numeric pain scale (NPS), and a subjective improvement rating scale. Baseline scores were compared to the most recent outcome scores at the time of the analysis and adjusted for demographic differences. We reported comparisons of pre- and post-treatment scores, the differences between osteoarthritis and rotator cuff groups, and the predictive effects on the clinical outcomes.

Results: At the most current follow-up assessment after treatment, the average DASH score decreased (improved) from 36.1 to $17.1(P<0.001)$ and the average numeric pain scale value decreased (improved) from 4.3 to $2.4(P<0.001)$. These changes were associated with an average subjective improvement of $48.8 \%$. No differences were observed between outcomes among the shoulders treated for OA versus rotator cuff tears, nor did age, sex, or body mass index influence pain or functional outcomes. There were no significant treatment-related adverse events reported.

Discussion: We observed preliminarily encouraging results following BMC injections for shoulder OA and rotator cuff tears. These results serve as basis for the design of an adequately powered randomized controlled trial.

Keywords: bone marrow concentrate, autologous mesenchymal stem cells, shoulder, pain, function

\section{Introduction}

Shoulder pain is the third most common musculoskeletal disorder observed in the primary care setting, after back and neck pain. ${ }^{1,2}$ Estimates of the point prevalence of shoulder pain in adults range from $7 \%$ to $27 \%$ in the population under the age of 70 and from $13 \%$ to $26 \%$ in adults 70 years and over. ${ }^{3}$ The lifetime prevalence of painful shoulder disorders is $10 \%$ in the United States, with an annual incidence of 15 new cases per 1,000 in the at-risk population. ${ }^{4}$ The insidious (ie, non-traumatic) onset of
Correspondence: Jamil Bashir

Centeno-Schultz Clinic,

403 Summit Blvd Suite 20I,

Broomfield, CO 80021 , USA

Tel + I 3034296448

Email jbashir@centenoschultz.

onmicrosoft.com 
shoulder pain is attributed to various degenerative and inflammatory processes, including disorders of the rotator cuff, adhesive capsulitis, and glenohumeral osteoarthritis (OA). ${ }^{5}$ In patients $>70$ years, the most common diagnosis associated with shoulder pain is a rotator cuff derangement. ${ }^{6}$ Persistent inflammatory and degenerative conditions are responsible for recurrent or chronic shoulder pain in $40 \%$ of patients, and disability associated with chronic shoulder pain significantly impacts the economy in the form of decreased productivity and health care costs. ${ }^{4,7,8}$

Arthroscopic surgery is a common approach for treating shoulder pain, and from 1996 to 2006, the number of these procedures increased by $600 \%$, including an overall $115 \%$ increase in the number of rotator cuff repairs. ${ }^{9}$ Arthroscopic surgery is technically challenging and complications or residual impairment related to the procedure, including stiffness, implant failure, nerve injury, and adhesive capsulitis, are estimated to range between $5.8 \%$ and $9.5 \% .^{10,11}$ It is estimated that recurrent defects occur in a very high proportion of cases, post-surgically. ${ }^{12,13}$

As an alternative to surgery, cell-based regenerative therapies, including the use of mesenchymal stem cells (MSCs), have shown promising results for the treatment of degenerative conditions of joints. ${ }^{14}$ MSCs are multipotent stem cells with the ability to differentiate into bone, cartilage, adipose, and muscle cells, and thus provide a means of facilitated tissue repair. ${ }^{15}$ Bone marrow is a rich source of MSCs, with the isolation and autologous transplantation of MSCs from bone marrow concentrate (BMC) having the advantage of avoiding immunogenic complications potentially associated with the use of allogeneic cell transplants. ${ }^{15,16}$

The clinical use of MSCs as an adjunct to surgical treatment of shoulder disorders has been described previously in the literature, ${ }^{17,18}$ including a study of 90 rotator cuff arthroscopy cases with a reported $100 \%$ positive outcome rate for procedures that used MSC-enriched BMC as an adjunctive therapy to the surgeries, a substantial increase in positive outcomes in comparison with procedures that did not use MSCs. ${ }^{19}$

Currently, there are no clinical studies that describe the treatment of painful shoulder conditions with $\mathrm{BMC}$ and MSCs alone. The clinical use of BMC injections for treatment of shoulder diseases requires analysis of the effectiveness of this approach. In the present study, we report on the symptomatic and functional outcomes for patients with painful shoulder disorders who were treated with BMC injections. As part of the analysis, we examined the impact of age, sex, and body mass index (BMI) on the reported outcomes.

\section{Methods}

\section{Study participants and data collection}

Patients were selected from a treatment registry designed to track the safety and efficacy of patients presenting to a network of 13 clinics providing treatment of joint disorders using autologous stem cells, BMC, or platelet-rich plasma (PRP). The registry was designed as an ongoing prospective survey system, using an automated questionnaire generated at 1 month, 3 months, 6 months, and 12 months and then annually post treatment, via an electronic database system using ClinCapture software (Clinovo Clinical Data Solutions, Sunnyvale, CA, USA; http://www.clinovo.com/clincapture). Baseline data are entered by registry staff who are also tasked with telephonic follow-up of patients who fail to respond to the electronic survey.

In the present study, patients with presenting symptoms of shoulder pain who were subsequently diagnosed with glenohumeral OA and/or partial or full-thickness rotator cuff tears were culled from the registry. Shoulder pathology was assessed by magnetic resonance imaging (MRI) and supported by findings from physical examination. All the patients included in the study had failed conservative therapies, such as physical therapy, medications, and test of time. Patients with less than a 3-month follow-up or a rotator cuff tear greater than $1.5 \mathrm{~cm}$ and evidence of retraction were excluded.

\section{Procedure description}

Patients were restricted from using corticosteroids and nonsteroidal anti-inflammatory drugs (NSAIDs) for 2 weeks preceding the procedure. This restriction was placed based on in vitro research revealing that corticosteroids and NSAIDs can have an inhibitory effect on MSCs. ${ }^{20}$ To prompt a brief inflammatory response before receiving the $\mathrm{BMC}$, patients were pre-injected with a hypertonic dextrose solution into the joint structures. ${ }^{21}$ Ultrasound or fluoroscopy was used to guide intra-articular or rotator cuff tear needle placement. When fluoroscopy was used to confirm intra-articular needle placement, iodixanol (Visipaque, NDC\# 0407-2223-06) radiographic contrast agent was injected followed by a second injection of 3-5 mL of $12.5 \%$ dextrose (NDC\# 0409-6648-02) and 0.1\% lidocaine (NDC\# $0409-4276-02$ ) or $0.25 \%$ ropivicaine (NDC\# 63323-286-23) in normal saline (NDC\# 0409-4888-50). Two to five days after the pre-injection, again using ultrasound or fluoroscopic guidance, $10-15 \mathrm{~mL}$ of bone marrow aspirate per 
bone site was collected from the patients' posterior superior iliac crest (total 60-90 mL) into heparinized syringes. For each $1 \mathrm{~mL}$ of whole bone marrow aspirate collected, 1,000 units of heparin (NDC\# 25021-403-01 and 25021-404-01) was added and the cell suspension was serially centrifuged, following which 1-3 mL of coagulated plasma containing white blood cells (termed buffy coat or the middle layer of the centrifuged bone marrow aspirate) was collected by manual serological pipetting. In addition to $\mathrm{BMC}$ isolation, $60 \mathrm{~mL}$ of intravenous blood was drawn for the isolation of PRP and platelet lysate (PL). These platelet products were used due to numerous studies demonstrating that the growth factors they contain can cause MSC proliferation. ${ }^{22}$ PRP was prepared by low-speed centrifugation $(200 \times g)$ to separate plasma and buffy coat layers from red blood cells and stored at $-20^{\circ} \mathrm{C}$. Subsequent PL was isolated by recentrifugation of PRP. All cell preparations were performed in sterile conditions under an ISO-5 class laminar flow cabinet located in an ISO-7 class clean room. The BMC injectate, containing PRP and PL, was transported via sterile means back to the operating room, where it was injected into the intra-articular structure and/or the rotator cuff tear under fluoroscopy or ultrasound guidance.

\section{Predictive factors}

Predictive factors examined in the study were age, BMI, sex, and type of the joint disease (ie, OA or rotator cuff tear). Rotator cuff tears were defined as including damage to the supraspinatus, infraspinatus, subscapularis, teres major, or teres minor tendons/muscles. Joints that had rotator cuff disorder associated with $\mathrm{OA}$ were classified in the rotator cuff group as the predominant cause of symptoms.

\section{Cell count data}

Cell count represents the total number of nucleated cells aspirated from the bone marrow and injected into the shoulder joint. Cell count data were accessed from a laboratory database (Centeno Schultz Clinic, Broomfield, CO, USA). Data were available for only one clinic. For cell counting, $5 \mu \mathrm{L}$ samples were obtained and red blood cells were lysed in $995 \mu \mathrm{L}$ of sterile distilled water (Thermo Fisher Scientific, Waltham, MA, USA). The number of cells was then manually counted for four times under a microscope (National Optical, Schertz, TX, USA) using a hemocytometer (Reichert Bright-Line; Hausser Scientific, Horsham, PA, USA). The average of the four counts was calculated. The cell count was obtained by multiplying the dilution factor, volume of the hemocytometer, and final volume of the sample.

\section{Outcomes}

The outcomes of interest were the disabilities of the arm, shoulder and hand (DASH) numeric pain scale (NPS) and the subjective improvement rating score as reported by the patient. The DASH is a validated functional scale that measures the disability of shoulder and upper extremities. ${ }^{23}$ The DASH score is derived from answers to 30 questions assessing various aspects of daily and recreational activities, in addition to specific symptoms, including pain, tingling, stiffness, and weakness, ${ }^{24}$ and ranges from 0 (no disability) to 100 (most severe disability). ${ }^{23}$

Pain severity was assessed using the NPS, a one-item questionnaire with eleven scoring levels ranging from 0 (no pain) to 10 (most severe pain). The NPS scale is a valid means of assessing various types of pain..$^{25,26}$ The minimal clinically important difference (MCID) was defined by 2-point reduction in the NPS score and 10-point reduction in the DASH score. ${ }^{23,26}$

For the subjective percentage improvement rating metric, patients were asked: "Compared to your condition prior to the procedure, what percent difference have you seen in your condition?" The response range was from $-100 \%$ (significantly worsened) to $100 \%$ (significantly improved), with zero indicating no change.

For each outcome metric, the baseline score was compared with the most recent score of 3 months or more months duration post treatment.

In order to track adverse events, patients were asked the following questions: "Did you experience any complications you believe may be due to the procedure (ie, infection, illness, etc)? If yes, please explain" and "Have you been diagnosed with any new illness since the procedure? If yes, please explain."

\section{Statistical analyses}

Pre-treatment (baseline) and most recent post-treatment clinical scores were reported using the means and standard deviations. The differences between the two scores were then examined using the Wilcoxon signed-rank test for dependent groups. The outcome differences (changes in the clinical scores) between OA and rotator cuff disorders were analyzed using the Wilcoxon rank sum test. Outcome analysis was performed on the most recent post-treatment clinical score, using the method of last observations carried forward. Analysis of outcome scores at each time-point was not plausible in the current study due to the magnitude of missing data. 
We also examined the frequency and proportion of joints that achieved the MCID (responders to treatment) and joints that failed to achieve the MCID for the DASH and NPS scales (non-responders to treatment). Wilcoxon rank sum and Fisher exact tests were applied to test the demographical differences (age, BMI, and sex) between responders and non-responders.

Linear regression analysis was used to examine the effect of predictive variables on the symptomatic and functional outcomes. First, models were constructed to examine the effect of baseline score, disease type, age, BMI, and sex on outcomes. Second, models were also constructed to examine the effect of cell count in addition to other covariates.

Responding to questionnaires (follow-up surveys) was analyzed. Responder bias was assessed by examining differences between baseline values for the non-responders versus the responders using logistic regression analysis. The analysis was adjusted for age, sex, and BMI.

SAS software version 9.4 was used for all analyses. ${ }^{27}$ The post hoc power analysis described in the discussion was performed using $\mathrm{G}^{*}$ Power 3.1 software. ${ }^{28}$

\section{Results}

During the period of September 2010 through January 2014, there were 115 shoulder joints in 102 patients meeting the inclusion criteria who were treated with same-day BMC injection procedures. Among the 115 shoulders, there were 81 (70.4\%) diagnosed with a rotator cuff tear and 34 (29.6\%) diagnosed with OA alone. See Table 1 for the demographic characteristics of the groups. DASH scores decreased by an average of $52.6 \%$, from 36.1 at baseline to 17.1 at final follow-up $(P<0.001)$. NPS decreased by $44.2 \%$, from 4.3 to $3.4(P<0.001)$. The average

Table I Baseline characteristics and differences between osteoarthritis and rotator cuff groups

\begin{tabular}{|c|c|c|c|c|c|c|c|}
\hline & \multicolumn{3}{|c|}{ Osteoarthritis } & \multicolumn{3}{|c|}{$\begin{array}{l}\text { Rotator cuff } \\
\text { disorder }\end{array}$} & \multirow[t]{2}{*}{$P$-value } \\
\hline & $\mathbf{N}$ & Mean & SD & $\mathbf{N}$ & Mean & SD & \\
\hline Age & 34 & 52.1 & 14.3 & 81 & 59.5 & 11.9 & $0.015^{*}$ \\
\hline BMI & 29 & 25.3 & 2.9 & 67 & 26.6 & 4.7 & $0.27 I$ \\
\hline \multirow[t]{2}{*}{ Cell count $\times 10^{8}$} & 24 & 3.85 & 2.15 & 57 & 4.99 & 3.37 & 0.116 \\
\hline & $\mathbf{N}$ & $\%$ & & $\mathbf{N}$ & $\%$ & & \\
\hline Sex & 34 & & & 81 & & & 0.137 \\
\hline Male & 27 & 79.4 & & 53 & 65.4 & & \\
\hline Female & 7 & 20.6 & & 28 & 34.6 & & \\
\hline
\end{tabular}

Notes: $\mathrm{N}$, observations with available data. * is statistically significant. $P$-values were calculated using the Wilcoxon rank sum test for age and BMI and chi-square test for the sex variable. Cell count, number of nucleated cells injected. Abbreviations: SD, standard deviation; BMI, body mass index. self-rated improvement was $48.8 \%$ compared to baseline (Table 2). The reduction in disability and pain was observed starting at the first month post treatment; mean DASH and NPS scores were 18.5 and 2.6, respectively (number of observations $[\mathrm{Ns}]=25$ for DASH; 30 for NPS). Improvement continued up to 2 years after treatment with means of 3.3 and 1.5 for DASH and NPS scales, respectively (Ns $=3$ for DASH; 8 for NPS).

The follow-up scores (last observations carried forward) for DASH and NPS were available for 40 and 55 joints, respectively. A total of 32 joints (58.2\%) achieved the MCID on the NPS scale (2 points reduction) and 26 joints (65\%) achieved the MCID on the DASH scale (10 points reduction). Demographical analysis showed that responders to treatment on the DASH scale (ie, joints achieving the MCID) were younger (mean age $=56.1$ years) and had higher female proportion (46.2\%); non-responders (joints failing to achieve the MCID) were $7.1 \%$ female and 65.3 years old in average $(P$-values $=0.025$ and 0.015 for age and sex comparisons, respectively). Regarding the NPS scale, there were no demographical differences between responders to treatment and non-responders.

There were no differences in outcomes between the OA and rotator cuff groups in either the univariate (Table 3) or multivariate analysis (Table 4). Age, BMI, and disease type did not demonstrate a measurable effect on the functional (DASH) and pain (NPS) outcomes in the linear regression model (Table 4). Although males reported a lower subjective improvement rating score, the effect of sex was not significant on DASH and NPS outcomes. DASH and NPS changes were significantly associated with the respective baseline scores $(P$-value $<0.001)$.

Table 2 Pre-treatment and post-treatment clinical scales, changes from the baseline, and mean follow-up periods in months for the study population

\begin{tabular}{lllll}
\hline Variable & N & Mean & SD & P-value \\
\hline DASH & & & & \\
$\quad$ Pre-treatment & 40 & 36.1 & 19.8 & - \\
$\quad$ Post-treatment & 40 & 17.1 & 12.6 & - \\
$\quad$ Difference & 40 & -19 & 18.8 & $<0.00 I^{*}$ \\
$\quad$ Follow-up period & 40 & 7.1 & 6.6 & - \\
NPS & & & & \\
$\quad$ Pre-treatment & 55 & 4.3 & 2.2 & - \\
$\quad$ Post-treatment & 55 & 2.4 & 2.1 & - \\
$\quad$ Difference & 55 & -1.9 & 2.4 & $<0.001 *$ \\
$\quad$ Follow-up period & 55 & 8.3 & 7.8 & - \\
Improvement rating score & & & & \\
$\quad$ Post-treatment & 85 & 48.8 & 44 & - \\
$\quad$ Follow-up period & 85 & 11.2 & 10 & - \\
\hline
\end{tabular}

Notes: $\mathrm{N}$, observations with available data. $*$ is statistically significant. $P$-values were calculated for intra-group differences using the Wilcoxon signed-rank test. Abbreviations: SD, standard deviation; DASH, disabilities of the arm, shoulder and hand scale; NPS, numeric pain scale. 
Table 3 Comparison between osteoarthritis and rotator cuff groups: changes in DASH, NPS, and reported subjective percentage improvement rating score

\begin{tabular}{|c|c|c|c|c|c|c|c|}
\hline & \multicolumn{3}{|c|}{ Osteoarthritis } & \multicolumn{3}{|c|}{ Rotator cuff } & \multirow[t]{2}{*}{$P$-value } \\
\hline & $\overline{\mathbf{N}}$ & Mean & SD & $\mathbf{N}$ & Mean & $\overline{S D}$ & \\
\hline Change in DASH & 10 & -18.7 & 11.2 & 30 & -19.1 & 20.9 & 0.963 \\
\hline Change in NPS & 14 & -1.6 & 2.1 & 41 & -2.1 & 2.5 & 0.308 \\
\hline $\begin{array}{l}\text { Improvement } \\
\text { rating score }\end{array}$ & 24 & 50.4 & 34.8 & 61 & 48.1 & 47.4 & 0.872 \\
\hline
\end{tabular}

Notes: $\mathrm{N}$, observations with available data. $P$-values were calculated for inter-group differences using the Wilcoxon rank sum test.

Abbreviations: SD, standard deviation; DASH, disabilities of the arm, shoulder and hand scale; NPS, numeric pain scale.

Nucleated cell count data were available for 81 joints. The mean cell count was $4.7 \times 10^{8}$ cells (standard deviation $=3.1$, range $=0.6-22.7$ ). Multivariate analyses (Table 5 ) showed that the impact of cell count on DASH, NPS, and improvement rating outcomes was not statistically significant.

Five adverse events were reported (4.9\% of patients), classified as pain $(\mathrm{N}=3)$, cardiac $(\mathrm{N}=1)$, and other $(\mathrm{N}=1)$. The three pain cases were possibly related to the procedure, and the other two were adjudicated as unlikely to be related to the procedure. There were no serious adverse events reported.

\section{Discussion}

Shoulder patients treated with BMC injections demonstrated substantial symptomatic and functional improvement at follow-up. Functional improvements exceeded the minimally

Table 4 The effect of baseline score, diagnosis of rotator cuff injury, age, and BMI on outcomes

\begin{tabular}{|c|c|c|c|c|}
\hline & $\mathbf{N}$ & Coefficient $(\beta)$ & SE & $P$-value \\
\hline Change in DASH score & 37 & & & \\
\hline Baseline score & & -0.65 & 0.11 & $<0.00 I^{*}$ \\
\hline Disease type (rotator cuff) & & -0.74 & 4.72 & 0.877 \\
\hline Age & & 0.28 & 0.18 & 0.136 \\
\hline BMI & & -0.18 & 0.64 & 0.777 \\
\hline Sex (male) & & 5.19 & 5.15 & 0.321 \\
\hline Change in NPS score & 52 & & & \\
\hline Baseline score & & -0.51 & 0.13 & $<0.00 I^{*}$ \\
\hline Disease type (rotator cuff) & & 0.14 & 0.66 & 0.835 \\
\hline Age & & -0.02 & 0.02 & 0.494 \\
\hline BMI & & -0.08 & 0.08 & 0.319 \\
\hline Sex (male) & & 0.74 & 0.67 & 0.275 \\
\hline Improvement rating score & 76 & & & \\
\hline Disease type (rotator cuff) & & -9.50 & 12.42 & 0.447 \\
\hline Age & & -0.24 & 0.43 & 0.589 \\
\hline BMI & & -0.17 & 1.55 & 0.915 \\
\hline Sex (male) & & -25.18 & 12.18 & $0.042^{*}$ \\
\hline
\end{tabular}

Note: *Statistically significant at $P \leq 0.05$. Cell count, number of nucleated cells injected.

Abbreviations: BMI, body mass index; SE, standard error; DASH, disabilities of the arm, shoulder, and hand scale; NPS, numeric pain scale; N, number of observations.
Table 5 Multivariate regression models including cell count as a predictive variable

\begin{tabular}{|c|c|c|c|c|}
\hline & $\mathbf{N}$ & Coefficient $(\beta)$ & SE & $P$-value \\
\hline Change in DASH score & 24 & & & \\
\hline Baseline score & & -0.54 & 0.23 & $0.034 *$ \\
\hline Disease type (rotator cuff) & & -5.19 & 9.02 & 0.572 \\
\hline Age & & 0.60 & 0.29 & 0.058 \\
\hline BMI & & -0.54 & 1.22 & 0.662 \\
\hline Sex (male) & & 4.36 & 8.97 & 0.633 \\
\hline Cell count & & 0.76 & 2.07 & 0.716 \\
\hline Change in NPS score & 36 & & & \\
\hline Baseline score & & -0.54 & 0.17 & $0.004 *$ \\
\hline Disease type (rotator cuff) & & 0.17 & 0.99 & 0.863 \\
\hline Age & & -0.02 & 0.03 & 0.546 \\
\hline BMI & & -0.12 & 0.14 & 0.390 \\
\hline Sex (male) & & 1.09 & 1.22 & 0.380 \\
\hline Cell count & & -0.05 & 0.17 & 0.764 \\
\hline Improvement rating score & 56 & & & \\
\hline Disease type (rotator cuff) & & -9.01 & 17.00 & 0.598 \\
\hline Age & & -0.53 & 0.58 & 0.364 \\
\hline BMI & & -1.47 & 2.13 & 0.494 \\
\hline Sex (male) & & -23.54 & 17.79 & 0.192 \\
\hline Cell count & & 1.90 & 3.01 & 0.530 \\
\hline
\end{tabular}

Notes: *Statistically significant at $P \leq 0.05$. Cell count $=\left(\times 10^{8}\right)$. Cell count, number of nucleated cells injected.

Abbreviations: SE, standard error; DASH, disabilities of the arm, shoulder and hand scale; BMI, body mass index; NPS, numeric pain scale; N, number of observations.

important difference defined as a 10-point change on the DASH scale. ${ }^{23}$ The $44.2 \%$ reduction in pain also exceeded the minimum important difference as defined by $30 \%$ decrease on the NPS scale. ${ }^{26}$ Improvement in pain and disability was observed at first month post-treatment and continued up to 2 years, which was the latest time-point obtained for the DASH and NPS scales. No serious adverse events were reported after the procedures.

Bone marrow aspirate is a rich source of MSCs, and the treatment effects observed in this study may be related to the regenerative characteristics of these cells. ${ }^{29}$ The regenerative capacity of bone marrow-derived MSCs has been demonstrated in several animal studies. ${ }^{30,31}$ These studies have demonstrated that MSC transplantation both repairs damaged tissue and restores function. The use of BMC for the treatment of shoulder conditions has already partly translated to clinical use; in one study of BMC use with rotator cuff surgery, the authors reported reduced retear rates, an indication of improved tendon integrity. ${ }^{19}$ The results in the present study are consistent with these results, but the more invasive surgery is absent.

Although age and sex were significantly different between responders to treatment and non-responders (as measured by DASH), the adjusted multivariate analyses showed that age, sex, and BMI did not predict the functional and pain outcomes. Our finding that neither age nor BMI had an impact on outcomes was also consistent with the findings of prior authors 
reporting on rotator cuff repairs and joint arthroplasty. ${ }^{32,33}$ Our finding that women reported greater subjective improvement ratings compared to males was surprising given that the functional and pain scales did not indicate better outcomes for women. This latter finding is also consistent with the reports from studies of shoulder surgery, in which sex has not been found to predict pain or functional outcome. ${ }^{34,35}$ Two recent studies have shown that joint's functional outcomes can be affected by sex, but it is unclear whether the sex effect is due to biological and/or anatomical differences between males and females or due to confounding factors. ${ }^{36,37}$ Patients with higher disability and pain metrics at baseline experienced the greatest improvements, possibly just an indication of regression to the mean, rather than an indication that the procedure is more successful in patients with more substantial symptoms. The finding that rotator cuff involvement did not affect outcome was consistent with previous reports of the efficacy of biologics and cell-based therapies for such conditions. ${ }^{19,38}$

The effect of stem cell dose variation on the efficacy of musculoskeletal injections is still unclear, and prior reports have been inconsistent. ${ }^{39-41}$ This is probably due to the fact that different methods, sources, cell doses, and types were used for the treatment of orthopedic disease. In this study, the number of nucleated cells within the BMC injection did not significantly impact clinical outcomes. Although we did not find a significant association between the injected cell dose and treatment outcome in this study; we emphasize that these are the results of a small group, and larger population studies are required to further explore the role of cell dose in the treatment of shoulder disease.

Limitations of our study include the subjective nature of the orthopedic scales and the inability to discriminate between subclasses of pathology in the registry data, as the dichotomous classification of either joint OA or rotator cuff does not capture the nuanced differences in disease severity in the group, and thus, there is no way to know why some patients responded better than others.

As a treatment registry study, there was a lack of a control group, which is always a concern with outcome studies. This is less of a concern for the size or even the validity of the effect observed, as the patients all served as their own controls. A larger issue is the fact that a placebo or other effect not related to the cellular/biologic therapy cannot be ruled out as the cause of the observed outcomes, nor can the effect of the BMC be differentiated from the PRP or hypertonic dextrose. As the final outcome values were recorded, an average of 7-11 months after the treatment, a placebo response seems unlikely.

Although we used both PRP and hypertonic dextrose in conjunction with the $\mathrm{BMC}$ injections, neither were employed for their curative effects on their own, nor was there reason to believe that either PRP or hypertonic dextrose would have a significant impact on the conditions treated in this study. Clinical studies of the efficacy of PRP injections alone for rotator cuff tears have not demonstrated significant benefit for the therapy. ${ }^{42,43}$ Although there are no studies of PRP for glenohumeral OA, studies of the therapy for the knee have shown either minimal or temporary benefit. ${ }^{44}$ Likewise, we were unable to find any publications, including animal models, indicating that dextrose alone can produce a healing effect of muscular or tendon injuries. ${ }^{45}$

There is additional concern regarding missing data and the possibility of the non-response bias. In the multivariate analyses, younger age and higher BMI were associated with non-response to the subjective improvement rating questionnaire, although non-response was not related to the severity of condition determined by baseline scores.

Despite these limitations, these study results are encouraging and portend what are potentially significant clinical implications. If indeed BMC injections can act as an intermediary treatment between non-invasive conservative care and rotator cuff surgery or joint arthroplasty, there is a large population of patients who could benefit. Our findings warrant further investigation with randomized and placebocontrolled studies, with long-term follow-up.

\section{Conclusion}

The use of BMC to treat symptomatic rotator cuff tears and glenohumeral OA is promising, and in an uncontrolled treatment registry population, effective at both reducing pain and improving function. Randomized clinical trials are required to confirm the efficacy of BMC injections for treatment of shoulder OA and rotator cuff tears.

\section{Disclosure}

Dr Christopher Centeno is a shareholder and director of Regenerative Sciences, LLC. Hasan Al-Sayegh is an employee of the Centeno Schultz Clinic, Regenerative Sciences, LLC. Dr Jamil Bashir is a fellow trainer at the Centeno Schultz Clinic. Dr Shaun Goodyear and Dr Michael Freeman have no conflicts of interest.

\section{References}

1. Urwin M, Symmons D, Allison T, et al. Estimating the burden of musculoskeletal disorders in the community: the comparative prevalence of symptoms at different anatomical sites, and the relation to social deprivation. Ann Rheum Dis. 1998;57(11):649-655.

2. Linsell L, Dawson J, Zondervan K, et al. Prevalence and incidence of adults consulting for shoulder conditions in UK primary care; patterns of diagnosis and referral. Rheumatology. 2006;45(2):215-221. 
3. Luime JJ, Koes BW, Hendriksen IJ, et al. Prevalence and incidence of shoulder pain in the general population; a systematic review. Scand J Rheumatol. 2004;33(2):73-81.

4. Van der Heijden GJ. Shoulder disorders: a state-of-the-art review. Baillières Best Pract Res Clin Rheumatol. 1999;13(2):287-309.

5. Meislin RJ, Sperling JW, Stitik TP. Persistent shoulder pain: epidemiology, pathophysiology, and diagnosis. Am J Orthop (Belle Mead NJ). 2005;34(12 Suppl):5-9.

6. Chard MD, Hazleman R, Hazleman BL, King RH, Reiss BB. Shoulder disorders in the elderly: a community survey. Arthritis Rheum. 1991; 34(6):766-769.

7. Virta L, Joranger P, Brox JI, Eriksson R. Costs of shoulder pain and resource use in primary health care: a cost-of-illness study in Sweden. BMC Musculoskelet Disord. 2012;13(1):17.

8. Vitale MA, Arons RR, Hurwitz S, Ahmad CS, Levine WN. The rising incidence of acromioplasty. J Bone Joint Surg Am. 2010;92(9): 1842-1850.

9. Colvin AC, Egorova N, Harrison AK, Moskowitz A, Flatow EL. National trends in rotator cuff repair. J Bone Joint Surg Am. 2012;94(3): 227-233.

10. Weber SC, Abrams JS, Nottage WM. Complications associated with arthroscopic shoulder surgery. Arthroscopy. 2002;18(2 Suppl 1): 88-95.

11. Voigt JD, Mosier M, Huber B. In-office diagnostic arthroscopy for knee and shoulder intra-articular injuries its potential impact on cost savings in the United States. BMC Health Serv Res. 2014;14(1):203.

12. Boileau P, Brassart N, Watkinson DJ, Carles M, Hatzidakis AM, Krishnan SG. Arthroscopic repair of full-thickness tears of the supraspinatus: does the tendon really heal? J Bone Joint Surg Am. 2005;87(6): 1229-1240.

13. Lafosse L, Brozska R, Toussaint B, Gobezie R. The outcome and structural integrity of arthroscopic rotator cuff repair with use of the double-row suture anchor technique. J Bone Joint Surg Am . 2007;89(7): 1533-1541.

14. Centeno CJ. Clinical challenges and opportunities of mesenchymal stem cells in musculoskeletal medicine. PM R. 2014;6(1):70-77.

15. Pittenger MF, Mackay AM, Beck SC, et al. Multilineage potential of adult human mesenchymal stem cells. Science. 1999;284(5411):143-147.

16. Galli D, Vitale M, Vaccarezza M. Bone marrow-derived mesenchymal cell differentiation toward myogenic lineages: facts and perspectives. Biomed Res Int. 2014;2014:6.

17. Beitzel K, Solovyova O, Cote MP, et al. The future role of mesenchymal stem cells in the management of shoulder disorders. Arthroscopy. 2013;29(10):1702-1711.

18. Isaac C, Gharaibeh B, Witt M, Wright VJ, Huard J. Biologic approaches to enhance rotator cuff healing after injury. J Shoulder Elbow Surg. 2012;21(2):181-190.

19. Hernigou P, Flouzat Lachaniette CH, Delambre J, et al. Biologic augmentation of rotator cuff repair with mesenchymal stem cells during arthroscopy improves healing and prevents further tears: a casecontrolled study. Int Orthop. 2014;38(9):1811-1818.

20. Wyles CC, Houdek MT, Wyles SP, Wagner ER, Behfar A, Sierra RJ. Differential cytotoxicity of corticosteroids on human mesenchymal stem cells. Clin Orthop. 2014;473(3):1155-1164.

21. Jensen KT, Rabago DP, Best TM, Patterson JJ, Vanderby R. Early inflammatory response of knee ligaments to prolotherapy in a rat model. J Orthop Res. 2008;26(6):816-823.

22. Rubio-Azpeitia E, Andia I. Partnership between platelet-rich plasma and mesenchymal stem cells: in vitro experience. Muscles Ligaments Tendons J. 2014;4(1):52-62.

23. Gummesson C, Atroshi I, Ekdahl C. The disabilities of the arm, shoulder and hand (DASH) outcome questionnaire: longitudinal construct validity and measuring self-rated health change after surgery. $B M C$ Musculoskelet Disord. 2003;4:11.

24. Kurer M, Gooding C. The disabilities of the arm, shoulder and hand (DASH) score. Orthop Scores. 2014. Available from: http://www. orthopaedicscore.com/scorepages/disabilities_of_arm_shoulder_hand score_dash.html. Accessed December 2, 2014.
25. Childs JD, Piva SR, Fritz JM. Responsiveness of the numeric pain rating scale in patients with low back pain. Spine. 2005;30(11): 1331-1334.

26. Farrar JT, Young JP Jr, LaMoreaux L, Werth JL, Poole RM. Clinical importance of changes in chronic pain intensity measured on an 11-point numerical pain rating scale. Pain. 2001;94(2):149-158.

27. SAS Institute Inc. 2014. SAS software version 9.4.

28. Faul F, Erdfelder E, Lang A-G, Buchner AG. *Power 3: a flexible statistical power analysis program for the social, behavioral, and biomedical sciences. Behav Res Methods. 2007;39(2):175-191.

29. Smiler D, Soltan M, Albitar M. Toward the identification of mesenchymal stem cells in bone marrow and peripheral blood for bone regeneration. Implant Dent. 2008;17(3):236-247.

30. Gulotta LV, Kovacevic D, Packer JD, Deng XH, Rodeo SA. Bone marrow-derived mesenchymal stem cells transduced with scleraxis improve rotator cuff healing in a rat model. Am J Sports Med. 2011;39(6):1282-1289.

31. Yokoya S, Mochizuki Y, Natsu K, Omae H, Nagata Y, Ochi M. Rotator cuff regeneration using a bioabsorbable material with bone marrowderived mesenchymal stem cells in a rabbit model. Am J Sports Med. 2012;40(6):1259-1268.

32. Li X, Williams PN, Nguyen JT, Craig EV, Warren RF, Gulotta LV. Functional outcomes after total shoulder arthroplasty in obese patients. J Bone Joint Surg Am. 2013;95(21):e160.

33. Oh JH, Kim SH, Kang JY, Oh CH, Gong HS. Effect of age on functional and structural outcome after rotator cuff repair. Am J Sports Med. 2010;38(4):672-678.

34. Hettrich CM, Weldon E 3rd, Boorman RS, Parsons IM 4th, Matsen FA 3rd. Preoperative factors associated with improvements in shoulder function after humeral hemiarthroplasty. J Bone Joint Surg Am. 2004; 86-A(7):1446-1451.

35. Mok D, Wang E. Does age or gender of the patient influence the outcome of type II superior labrum anterior and posterior repair? Int J Shoulder Surg. 2012;6(4):112.

36. Chimera NJ, Smith CA, Warren M. Injury history, sex, and performance on the functional movement screen and Y balance test. J Athl Train. In press. 2015

37. Anderson BE, Neumann M, Huxel Bliven KC. Functional movement screen differences between male and female secondary school athletes. J Strength Cond Res Natl Strength Cond Assoc. 2014;29(4): 1098-1106.

38. Nixon AJ, Watts AE, Schnabel LV. Cell- and gene-based approaches to tendon regeneration. J Shoulder Elb Surg. 2012;21(2):278-294.

39. Kristjánsson B, Honsawek S. Current perspectives in mesenchymal stem cell therapies for osteoarthritis. Stem Cells Int. 2014;2014:e194318.

40. Vangsness CT, Farr J, Boyd J, Dellaero DT, Mills CR, LeRouxWilliams M. Adult human mesenchymal stem cells delivered via intraarticular injection to the knee following partial medial meniscectomy: a randomized, double-blind, controlled study. J Bone Joint Surg Am. 2014;96(2):90-98.

41. Pettine KA, Murphy MB, Suzuki RK, Sand TT. Percutaneous injection of autologous bone marrow concentrate cells significantly reduces lumbar discogenic pain through 12 months. Stem Cells Dayt Ohio. 2015; 33(1):146-156.

42. Charousset C, Zaoui A, Bellaïche L, Piterman M. Does autologous leukocyte-platelet-rich plasma improve tendon healing in arthroscopic repair of large or massive rotator cuff tears? Arthroscopy. 2014;30(4): 428-435.

43. Rodeo SA, Delos D, Williams RJ, Adler RS, Pearle A, Warren RF. The effect of platelet-rich fibrin matrix on rotator cuff tendon healing: a prospective, randomized clinical study. Am J Sports Med. 2012;40(6): 1234-1241.

44. Tietze DC, Geissler K, Borchers J. The effects of platelet-rich plasma in the treatment of large-joint osteoarthritis: a systematic review. Phys Sportsmed. 2014;42(2):27-37.

45. Kunduracioglu B, Ulkar B, Sabuncuoglu BT, Can B, Bayrakci K. Effects of hypertonic dextrose on injured rat skeletal muscles. Neurosciences (Riyadh). 2006;11(2):93-96. 
Journal of Pain Research

Dovepress

\section{Publish your work in this journal}

The Journal of Pain Research is an international, peer-reviewed, open access, online journal that welcomes laboratory and clinical findings in the fields of pain research and the prevention and management of pain. Original research, reviews, symposium reports, hypothesis formation and commentaries are all considered for publication.

The manuscript management system is completely online and includes a very quick and fair peer-review system, which is all easy to use. Visit http://www.dovepress.com/testimonials.php to read real quotes from published authors.

Submit your manuscript here: http://www.dovepress.com/journal-of-pain-research-journal 